\title{
Monitoring of Lung Edema by Microwave Reflectometry during Lung Ischemia-Reperfusion Injury in vivo
}

\author{
Kai Nowak ${ }^{a}$ Michael Schaefer ${ }^{b}$ Wolfgang Gross ${ }^{b}$ Roman Patrick Metzger ${ }^{c}$ \\ Peter Hohenberger $^{a}$ Stefan Post $^{a}$ Martha Maria Gebhard ${ }^{b}$ \\ ${ }^{a}$ Department of Surgery, Clinical Medical Faculty Mannheim, University of Heidelberg, Mannheim, \\ ${ }^{b}$ Experimental Surgery, Faculty of Medicine, University of Heidelberg, Heidelberg, and \\ ${ }^{\mathrm{c}}$ Department of Pediatric Surgery, University of Munich, Munich, Germany
}

\section{Key Words}

Microwave reflectometry $\cdot$ Lung ischemia $\cdot$ Lung edema $\cdot$ Thoracic surgery

\begin{abstract}
It is still unclear whether lung edema can be monitored by microwave reflectometry and whether the measured changes in lung dry matter content (DMC) are accompanied by changes in $\mathrm{PaO}_{2}$ and in pro- to anti-inflammatory cytokine expression (IFN- $\gamma$ and IL-10). Right rat lung hili were cross-clamped at $37^{\circ} \mathrm{C}$ for $0,60,90$ or $120 \mathrm{~min}$ ischemia followed by $120 \mathrm{~min}$ reperfusion. After $90 \mathrm{~min}$ (DMC: $15.9 \pm 1.4 \% ; \mathrm{PaO}_{2}: 76.7 \pm 18 \mathrm{~mm} \mathrm{Hg}$ ) and $120 \mathrm{~min}$ ischemia (DMC: $12.8 \pm 0.6 \% ; \mathrm{PaO}_{2}: 43 \pm 7 \mathrm{~mm}$ $\mathrm{Hg}$ ), a significant decrease in $\mathrm{DMC}$ and $\mathrm{PaO}_{2}$ throughout reperfusion compared to $0 \mathrm{~min}$ ischemia (DMC: $19.5 \pm$ $1.11 \% ; \mathrm{PaO}_{2}: 247 \pm 33 \mathrm{~mm} \mathrm{Hg} ; \mathrm{p}<0.05$ ) was observed. DMC and $\mathrm{PaO}_{2}$ decreased after 60 min ischemia but recovered during reperfusion (DMC: $18.5 \pm 2.4 \%$; $\mathrm{PaO}_{2}$ : $173 \pm 30 \mathrm{~mm} \mathrm{Hg}$ ). DMC values reflected changes on the physiological and molecular level. In conclusion, lung edema monitoring by microwave reflectometry might become a tool for the thoracic surgeon.
\end{abstract}

Copyright (C) 2006 S. Karger AG, Base

\section{Background}

Pathophysiological changes during ischemia and reperfusion in lung transplantation and pulmonary embolism trigger inflammatory responses leading to pulmonary ede$\mathrm{ma}$ and are a source of considerable mortality [1]. Ischemia-reperfusion injury has been found to have an impact on the gain of lung dry-to-wet weight and on pro- to antiinflammatory cytokine levels [2,3]. Experimental data are still lacking about the influence of the duration of ischemia during the early period of reperfusion in vivo on molecular expression in lung tissue and on development of pulmonary edema. Warm ischemic tolerance of nonventilated lung tissue has been shown to be between 1 and several hours [4-7]. Eppinger et al. [8] established an in situ and an in vivo ischemia-reperfusion model of the left rat lung to study pathophysiological changes during $90 \mathrm{~min}$ of ischemia followed by reperfusion.

Continuous monitoring of lung edema formation might therefore be of special interest in experimental and perioperative thoracic surgery. Recently, our group has demonstrated a linear correlation between two methods to measure the lung dry-to-wet weight ratio, namely either by drying and weighing or by microwave reflectometry measurements [9]. This microwave-based measurement technique was used to monitor lung edema during ischemia-reperfusion in order to investigate whether lung

Dr. Kai Nowak

Department of Surgery, Clinical Medical Faculty Mannheim

Theodor-Kutzer-Ufer 1-3, DE-68167 Mannheim (Germany)

Tel. +49621383 2225, Fax +496213833809

E-Mail kai.nowak@chir.ma.uni-heidelberg.de
Fax +41613061234 E-Mail karger@karger.ch www.karger.com

\section{$0014-312 X / 06 / 0381-0018 \$ 23.50 / 0$}

Accessible online at:

www.karger.com/esr 
edema correlates with a functional loss or with an increase in inflammatory parameters. An in situ and in vivo ischemia-reperfusion model of the right rat lung was used to evaluate lung injury after a period of up to $2 \mathrm{~h}$ of ischemia at $37^{\circ} \mathrm{C}$ followed by $2 \mathrm{~h}$ of reperfusion. Lung injury was determined by measuring arterial oxygen pressure $\left(\mathrm{PaO}_{2}\right)$ levels, pro- and anti-inflammatory cytokine levels and edema formation. At the end of each experiment the results of dry matter content (DMC) obtained by microwave reflectometry were compared with the DMC determined by drying and weighing.

\section{Methods}

\section{Animal Model}

Male Wistar rats weighing 350-400 g were used in all experiments. Experiments have been approved by the ethics committee of the University of Heidelberg and animals received humane care in compliance with the European Convention on Animal Care (GV solas guidelines) throughout the experiments.

Anesthesia and analgesia were induced by $50 \mathrm{mg}$ pentobarbital i.p. and $10 \mathrm{mg}$ of ketamine i.m. The animal was placed on a heated plate. Catheters placed in the jugular vein and carotid artery monitored systemic pressures. Pressure-controlled ventilation was performed after tracheotomy and introduction of a 10-gauge cannula by a rodent ventilator (RUS-1301, Foehr Medical Instruments, Germany) at $60 / \mathrm{min}, \mathrm{FiO}_{2}$ 0.5. After these procedures, anesthesia and analgesia were maintained by continuous intravenous application of $45 \mathrm{mg} / \mathrm{kg} / \mathrm{h}$ ketamine, $0.6 \mathrm{mg} / \mathrm{kg} / \mathrm{h}$ midazolam and $0.24 \mathrm{mg} / \mathrm{kg} / \mathrm{h}$ pancuronium.

A horizontal thoracotomy was performed to open the thorax anteriorly through the 6 th intercostal space and parasternally until the first ribs. Two clamps were placed and muscles and intercostal vessels were ligated successively to avoid excessive bleeding (fig. 1).

All animals received $100 \mathrm{IU}$ of heparin intravenously $15 \mathrm{~min}$ prior to ischemia to avoid thromboembolic events.

After careful preparation (fig. 1), the hilus of the right lung including upper, middle and lower lobes was laced by a silicone tube (OD $0.96 \mathrm{~mm}$; Neolab, Heidelberg, Germany) in order be used later as a tourniquet.

For ischemia the tourniquet was pulled tight at expiration. The thorax was covered by a wet compress and a heating blanket coupled to a second heating blanket underneath the animal. Using a thermometer placed between the right middle and lower lobes the heating system guaranteed a temperature of $37 \pm 0.25^{\circ} \mathrm{C}$ after $30 \mathrm{~min}$ of ischemia (fig. 2). During ischemia, the animals were ventilated at a frequency of $80 \mathrm{cycles} / \mathrm{min}$ at a flow of $0.8 \mathrm{1} / \mathrm{min}$ and a peak pressure of $150 \mathrm{~mm} \mathrm{H}_{2} \mathrm{O}$.

For reperfusion, the lace was removed and alveolar recruitment was performed over a period of $5 \mathrm{~s}$ at a peak inspiratory pressure below $200 \mathrm{~mm} \mathrm{H}_{2} \mathrm{O}$; thereafter the animals were ventilated at 60 cycles/min and a peak pressure of $150 \mathrm{~mm} \mathrm{H}_{2} \mathrm{O}$.

\section{Experimental Protocol}

Animals were randomized to investigate the extent of reperfusion injury after $60(\mathrm{I}-60 ; \mathrm{n}=5), 90(\mathrm{I}-90 ; \mathrm{n}=6)$ and $120 \mathrm{~min}$

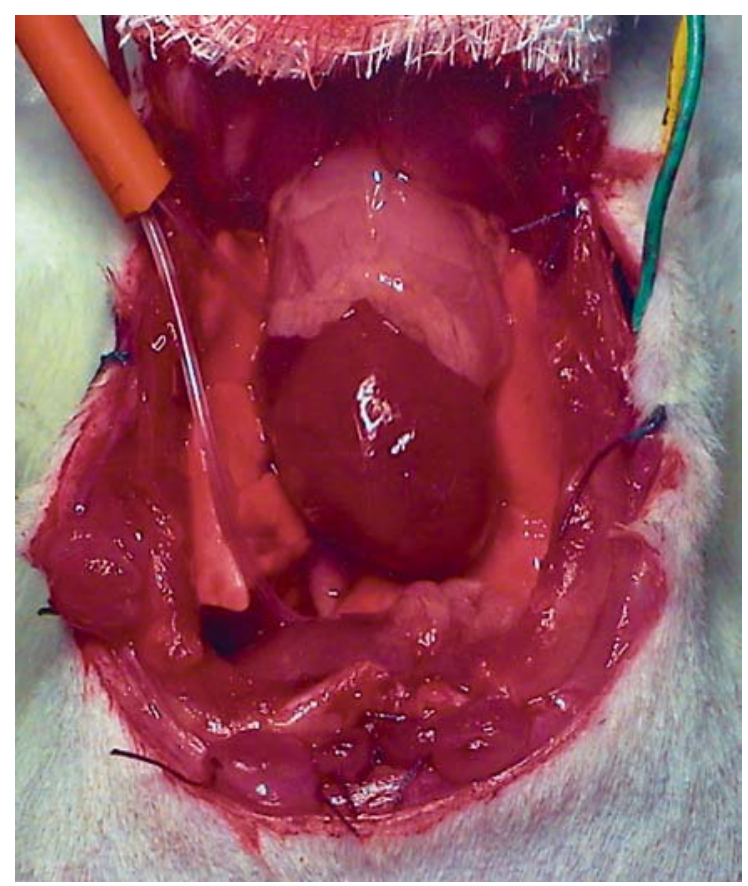

Fig. 1. Surgical procedure. Hili of the right lung including upper, middle and lower lobes were laced by a silicone tube. For ischemia, the tourniquet was pulled tight.

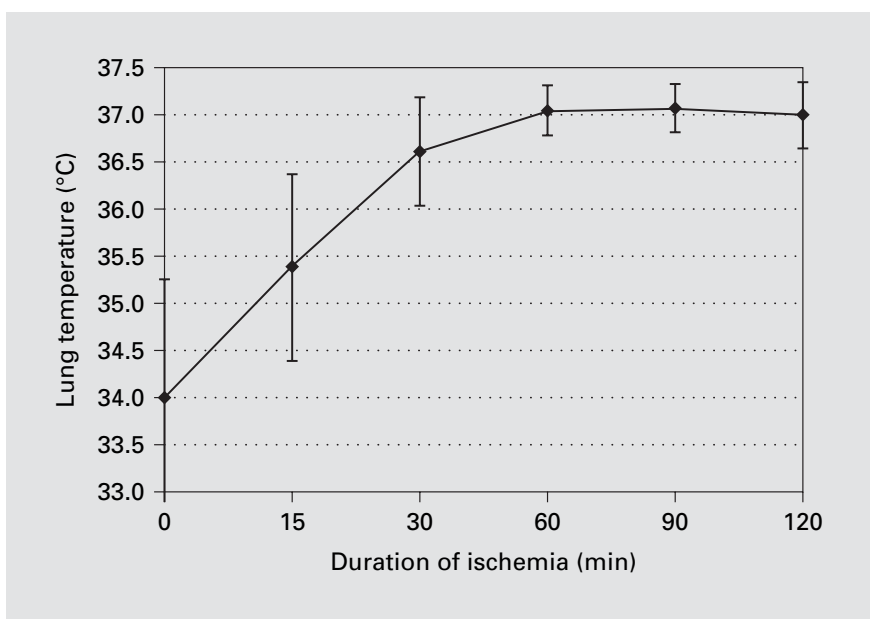

Fig. 2. Organ temperature. The organ temperature of the right lung during ischemia rose above $36.5^{\circ} \mathrm{C}$ within the first $30 \mathrm{~min}$ of ischemia and did not exceed $37.2^{\circ} \mathrm{C}$ in all investigated groups.

$(\mathrm{I}-120 ; \mathrm{n}=3)$ of ischemia at $37^{\circ} \mathrm{C}$ over a reperfusion period of 120 min versus sham-operated controls (sham; $n=6$ ).

Systemic pressure and blood gases were monitored before ischemia (T1), at the start of ischemia (T2), at the end of ischemia (T3), at the start of reperfusion (T4) and at $30 \mathrm{~min}$ (T5), $60 \mathrm{~min}$ (T6) and 
120 min of reperfusion (T7). The hemoglobin content of arterial blood was determined at the end of each experiment.

\section{Cytokine mRNA Expression Analysis}

Rats were sacrificed after $2 \mathrm{~h}$ of reperfusion. Thoracic organs were removed en bloc, and parts of the right lower lung lobe were shock frozen in liquid nitrogen. Total RNA was extracted using the Rneasy ${ }^{\circledR}$ kit (Qiagen, Hilden, Germany) with brief homogenization in a Miccra ${ }^{\circledR}$ D-8 homogeniser (Art-moderne Labortechnik, Müllheim-Hügelheim, Germany) and with the usage of the QIAshred$\operatorname{der}^{\circledR}$ (Qiagen). cDNA synthesis was performed using oligo-dT primers and Superscrit II ${ }^{\circledR}$ (Invitrogen, Kalsruhe, Germany) with $4 \mu \mathrm{g}$ of RNA according to the manufacturer's instructions.

PCR was performed as described elsewhere [10], using one eighth of the synthesized cDNA. The amounts of PCR products were determined by the Chemi Doc ${ }^{\circledR}$ and the Quantity One ${ }^{\circledR}$ (BioRad, Munich, Germany). The results were arbitrarily normalized to the signals of $\beta$-actin cDNA. The primers used for amplification of $\beta$-actin, interleukin (IL) 10 and interferon (IFN) $\gamma$, are described elsewhere [10].

\section{Edema Formation}

Dry weight was determined by microwave reflectometry after opening of the thoracic cavity, during ischemia and during reperfusion. The results were compared to the DMC measured by drying and weighing lung tissue at $100^{\circ} \mathrm{C}$ for $48 \mathrm{~h}$ after each experiment to ensure safe electrical contact between the lung tissue surface and the probe. This check was performed in the right middle lobe and the left upper lobe.

\section{Determination of Dry-to-Wet Ratio by Microwave}

Reflectometry

The dielectric properties of lung tissue were measured with an open-ended coaxial line probe, which was positioned in smooth contact with the lung surface. Measurements were performed before, at the beginning and end of ischemia, and at 0,30,60 and $120 \mathrm{~min}$ of reperfusion (T1-T7).

The probe diameter of the inner and outer conductor was 0.75 and $4 \mathrm{~mm}$, respectively, which resulted in a penetration depth of $2.5 \mathrm{~mm}$ into the tissue corresponding to a sample volume of $33 \mathrm{~mm}^{3}$. The complex reflection coefficient of the interface between coaxial line and tissue was measured from $5 \mathrm{MHz}$ to $3 \mathrm{GHz}$ using a network analyzer HP $8753 \mathrm{C}$ in combination with an $\mathrm{S}$ parameter test set HP 86046 A (Hewlett Packard Co., Palo Alto, Calif., USA). The complex dielectric permittivity of the lung tissue was calculated from the reflection coefficient measured after system calibration as described elsewhere [11]. It took $25 \mathrm{~s}$ to acquire 1 spectrum.

We fitted 3 Debye spectral terms [12] (see equation 1) to the measured data, in order to extract the high-frequency dielectric permittivity $\varepsilon_{w-t i s s u e}$ related to tissue water content.

$$
\varepsilon(\omega)=\varepsilon(\infty)+\frac{\sigma}{i \omega \varepsilon_{0}}+\sum_{j=1}^{3} \frac{\Delta \varepsilon_{j}}{1+i \omega \tau_{j}}
$$

with $\varepsilon_{0}=8.85 \times 10^{-12} \mathrm{As} / \mathrm{Vm}, \omega=2 \pi f, f=$ frequency, $i=$ imaginary unit $(=\sqrt{ }-1), \varepsilon(\infty)=5$. The parameters $\Delta \varepsilon_{j}, \tau_{j}, j=1,2,3$ and $\sigma$ were subjected to a nonlinear least-square fitting algorithm. The relaxation time $\tau_{3}$ was found to be at about $10^{-11} \mathrm{~s}$, which is in the region of the relaxation time measured in pure water [13]. Therefore, we identified $\Delta \varepsilon_{3}$ with the contribution of tissue water and the dielectric permittivity $\varepsilon_{w-t i s s u e}$ was calculated with:

$$
\varepsilon_{w-\text { tissue }}=\Delta \varepsilon_{3}+\varepsilon(\infty) \text {. }
$$

To determine the content of dry matter from the dielectric permittivity measurements we used a new dielectric model of lung tissue [9] describing the tissue as a mixture of water with the dielectric permittivity $\varepsilon_{w}=75$ [13], dry matter with $\varepsilon_{d r y}=3$ [14] and air with $\varepsilon_{\text {air }}=1$, each component having a corresponding volume fraction $v_{i}$, with $i=w, d r y$, air. Applying this model, the volume fraction $v_{w}$ of water was calculated with the mixture formula of:

$$
v_{W}=1-v_{d r y}-\frac{\varepsilon_{W-t i s s u e}-\varepsilon_{W}-v_{d r y}\left(\varepsilon_{d r y}-\varepsilon_{W}\right)\left[\frac{\varepsilon_{W-t i s s u e}+2 \varepsilon_{W}}{2 \varepsilon_{W}+\varepsilon_{d r y}}\right]}{\left(1-\varepsilon_{W}\right)\left[\frac{\varepsilon_{W-t i s s u c}+2 \varepsilon_{W}}{2 \varepsilon_{W}+1}\right]}
$$

and the content of dry matter $D M C_{d i e l}$ with equation 4 using $v_{d r y}=$ 0.098 [9]:

$$
D M C_{d i e l}=\frac{\rho_{d r y} v_{d r y}}{\rho_{w} v_{w}+\rho_{d r y} v_{d r y}}
$$

with $\rho_{d r y}=1.4 \mathrm{~g} / \mathrm{cm}^{3}[15]$ and $\rho_{w}=1.0 \mathrm{~g} / \mathrm{cm}^{3}$. Analogously, equation 5 was used for the calculation of $D M C_{\text {weight }}$ that was determined by drying and weighing:

$$
D M C_{\text {weight }}=\frac{m_{d r y}}{m_{\text {wet }}}=\frac{m_{d r y}}{m_{w}+m_{d r y}}=\frac{\rho_{d r y} v_{d r y}}{\rho_{w} v_{w}+\rho_{d r y} v_{d r y}}
$$

with mass $m_{i}, i=$ wet, $d r y$ of the wet and the dry tissue.

\section{Histological Sections}

Samples were taken from the medial superior part of the right lower lung lobe, put in specimen molds, filled and covered with Tissue-Tek (Sakura, Zoeterwoude, Netherlands) and were put into liquid nitrogen to be stored at $-80^{\circ} \mathrm{C}$ thereafter. Native tissues were sectioned at $5 \mu \mathrm{m}$ by a cryostat microtome (CM 3000, Leica/Jung, Germany). The slides were air-dried at room temperature for $12-$ $24 \mathrm{~h}$ and then were either processed directly or stored at $-30^{\circ} \mathrm{C}$. Histological evaluation was performed blinded for all specimens by standardized HE and PAS staining.

\section{Statistical Analysis}

For group comparison, the results were quoted as means \pm STD (standard deviation). Statistical differences between data sets during ischemia and reperfusion (T1-T7) were calculated using ANOVA multivariant analysis followed by the double-sided post hoc test of Dunnet. Statistical differences of expression analysis were calculated by the nonparametric rank sum test of Mann, Whitney and White. The null hypothesis was rejected when $\mathrm{p} \leq 0.05$.

To compare $D M C_{\text {diel }}$ from dielectric measurements with the results from drying and weighing, the lung tissue $D M C_{\text {weight }}$, we used the statistical method of Bland and Altman [16].

\section{Results}

Lung temperature during ischemia was adjusted to $37.0^{\circ} \mathrm{C}$ which was reached about $30 \mathrm{~min}$ after the cooling period during the surgical preparation (fig. 2). At the end of each experiment, the hemoglobin content in arterial blood was similar in all investigated groups (control: 11.8 
Fig. 3. Changes in $\mathrm{PaO}_{2}$ values. A significant loss of $\mathrm{PaO}_{2}$ values occurred during the first $30 \mathrm{~min}$ of reperfusion in all investigated groups compared to sham-operated controls $(* \mathrm{p}<0.01)$, which persisted in I-90 over $2 \mathrm{~h}$ of reperfusion $(* \mathrm{p}<0.01)$. I-60 animals recovered from this loss of oxygenation whereas I-120 animals died.

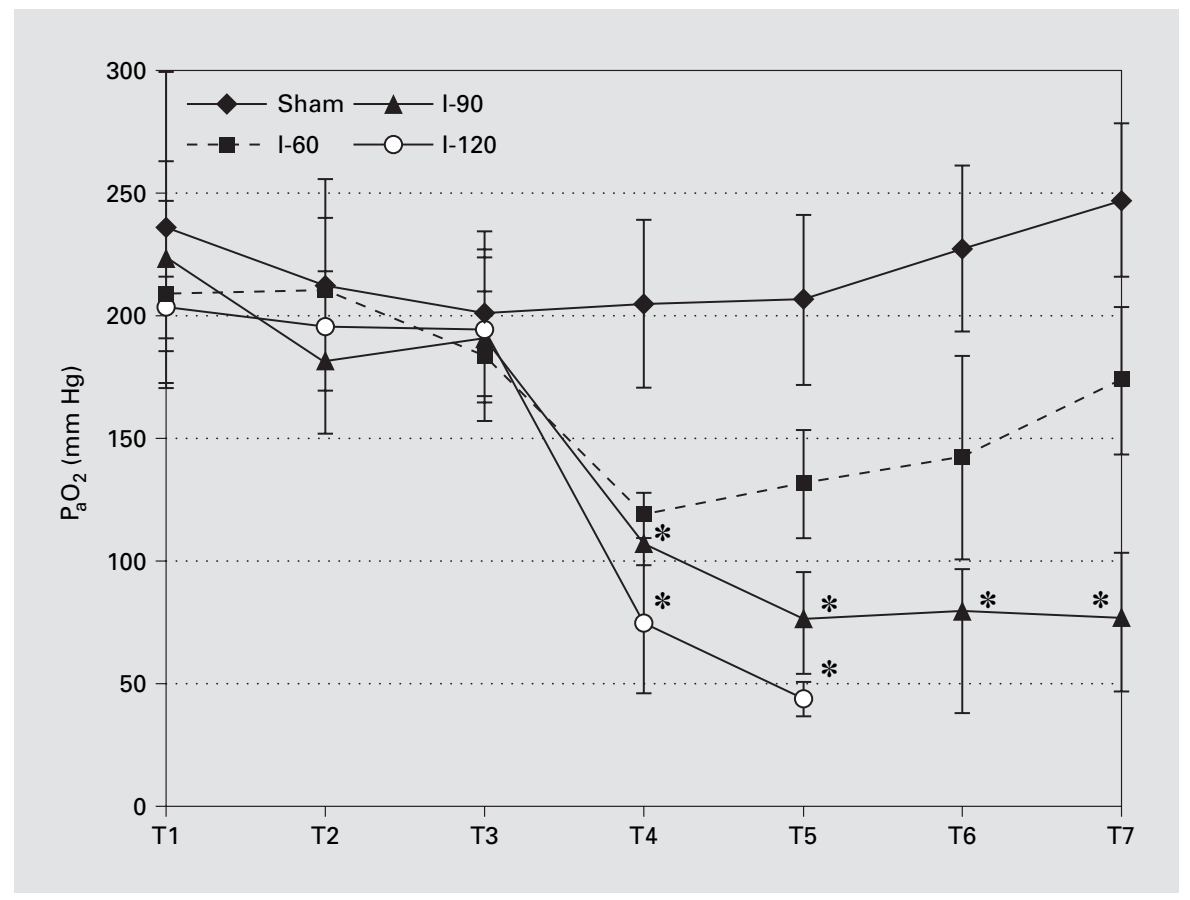

Table 1. Changes in arterial pressure $(\mathrm{mm} \mathrm{Hg})$

\begin{tabular}{llrrrrrr}
\hline & T1 & T2 & T3 & T4 & T5 & T6 & T7 \\
\hline Sham & $112.80 \pm 15.41$ & $115.40 \pm 13.22$ & $118.00 \pm 13.39$ & $120.00 \pm 13.81$ & $119.20 \pm 9.36$ & $112.80 \pm 10.64$ & $111.40 \pm 11.52$ \\
I-60 & $126.60 \pm 8.53$ & $99.56 \pm 56.36$ & $111.40 \pm 10.89$ & $110.40 \pm 16.41$ & $110.80 \pm 10.62$ & $108.40 \pm 10.74$ & $113.40 \pm 9.56$ \\
I-90 & $119.67 \pm 19.70$ & $107.17 \pm 22.53$ & $105.33 \pm 14.84$ & $83.883 \pm 8.79 *$ & $87.17 \pm 3.71 *$ & $83.33 \pm 5.32 *$ & $87.50 \pm 7.94 *$ \\
I-120 & $120.00 \pm 5.00$ & $113.33 \pm 17.55$ & $107.67 \pm 10.78$ & $74.33 \pm 20.64$ & $46.67 \pm 3.06$ & & \\
\hline
\end{tabular}

Stable arterial pressures were monitored in all groups. In I-90 animals, arterial pressures were lower during reperfusion compared to sham-operated controls $(* \mathrm{p}<0.05)$.

$\pm 1.1 \mathrm{~g} / \mathrm{dl} ; \mathrm{I}-60: 11.9 \pm 1.0 \mathrm{~g} / \mathrm{dl} ; \mathrm{I}-90: 11.0 \pm 0.9 \mathrm{~g} / \mathrm{dl} ;$ $\mathrm{I}-120: 11.4 \pm 1.0 \mathrm{~g} / \mathrm{dl})$.

Arterial oxygenation dropped throughout reperfusion in the contingent with 90 min of ischemia and was significantly reduced compared to sham-operated animals (I-90: $76.7 \pm 17.5 \mathrm{~mm} \mathrm{Hg}$; sham: $247.0 \pm 33.9 \mathrm{~mm} \mathrm{Hg}$; $\mathrm{p}<0.01$; table 1). After $120 \mathrm{~min}$ of ischemia, the animals developed lethal $\mathrm{PaO}_{2}$ values compared to sham-operated controls and died within $30 \mathrm{~min}$ of reperfusion (I120: $43.7 \pm 7.1 \mathrm{~mm} \mathrm{Hg}$; sham: $206.4 \pm 34.7 \mathrm{~mm} \mathrm{Hg}$; $\mathrm{p}<0.01) . \mathrm{PaO}_{2}$ values of $\mathrm{I}-60$ animals dropped during the first $30 \mathrm{~min}$ of reperfusion compared to controls, but recovered thereafter compared to sham-operated controls (fig. 3).
The comparison of $D M C_{\text {diel }}$ at the end of each experiment with $D M C_{\text {weight }}$ found by drying and weighing in the Bland-Altman plot in figure 4 shows that $95 \%$ of all differences were within the limit of $\pm 2.3 \%$.

A significant decrease in $D M C_{\text {diel }}$ was observed during the first $30 \mathrm{~min}$ of reperfusion (T5) in I-90 and I-120 (sham: $19.1 \pm 1.50 \%$; I-90: $16.2 \pm 2.30 \%$; I-120: $12.8 \pm$ $0.60 \% ; \mathrm{p}<0.05)$ and at T7 of I-90 compared to sham-operated controls (I-90: $15.4 \pm 1.43 \%$; sham: $19.5 \pm 1.11 \%$; $\mathrm{p}<0.05$, fig. 5). $D M C_{\text {diel }}$ in group I-60 also showed a minimum at T3 (n.s.), but in contrast to I-90 and I-120 a recovery to control values was observed at $\mathrm{T} 7$.

At the end of each experiment a significant increase in IFN- $\gamma$ on $\beta$-actin expression was observed in lung 
Fig. 4. Correlation of the dry-to-wet ratio determined by different methods. BlandAltman plot for comparison of DMC determined by drying and weighing $\left(D M C_{\text {weight }}\right)$ and by microwave reflectometry $\left(D M C_{\text {diel }}\right)$. The data were pooled from all groups and were measured at the right middle lobe and the left upper lobe in each experiment.
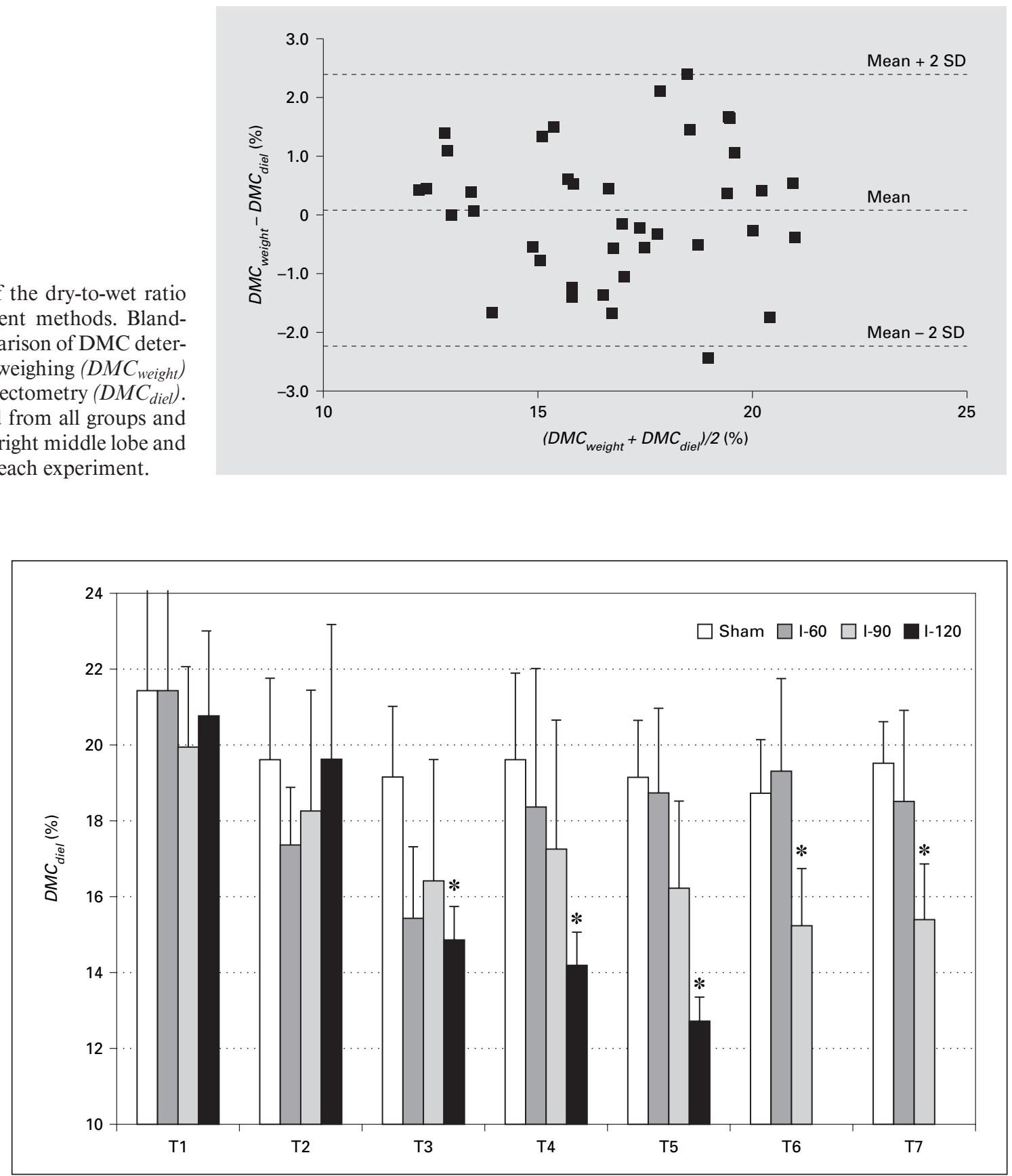

Fig. 5. Changes in lung DMC. Lung $D M C_{\text {diel }}$ determined by microwave reflectometry prior, during and after ischemia showed a significant loss of lung dry-to-wet ratio in I-90 and I-120 animals compared to sham-operated controls $(* \mathrm{p}<0.05)$. In animals of I-60, the initial loss of $D M C_{\text {diel }}$ during reperfusion recovered until the end of the experiment compared to sham-operated controls.

tissue of the I-90 group compared to controls (I-90: $1.068 \pm 0.049$; sham: $0.433 \pm 0.041 ; \mathrm{p}<0.01$; fig. 6). The increase in IFN- $\gamma$ expression resulted in an increased pro- to anti-inflammatory cytokine expression of IFN- $\gamma / \mathrm{IL}-10$ in this group (I-90: $3.311 \pm 0.535$; sham: $1.636 \pm 0.132 ; \mathrm{p}<0.01$; fig. 6). I-60 and I-90 animals did not show a significant increase in neither IFN- $\gamma$ nor IL-10 (fig. 6). 
Fig. 6. mRNA expression analysis. Lung tissue expression analysis of IFN- $\gamma$ and IL10 at the end of each experiment: a significant elevation of IFN- $\gamma$ on $\beta$-actin expression and on IFN- $\gamma$ on IL-10 expression was observed in I-90 compared to controls $(* \mathrm{p}<0.01)$. No significant changes were observed in IL-10 on $\beta$-actin expression analysis.

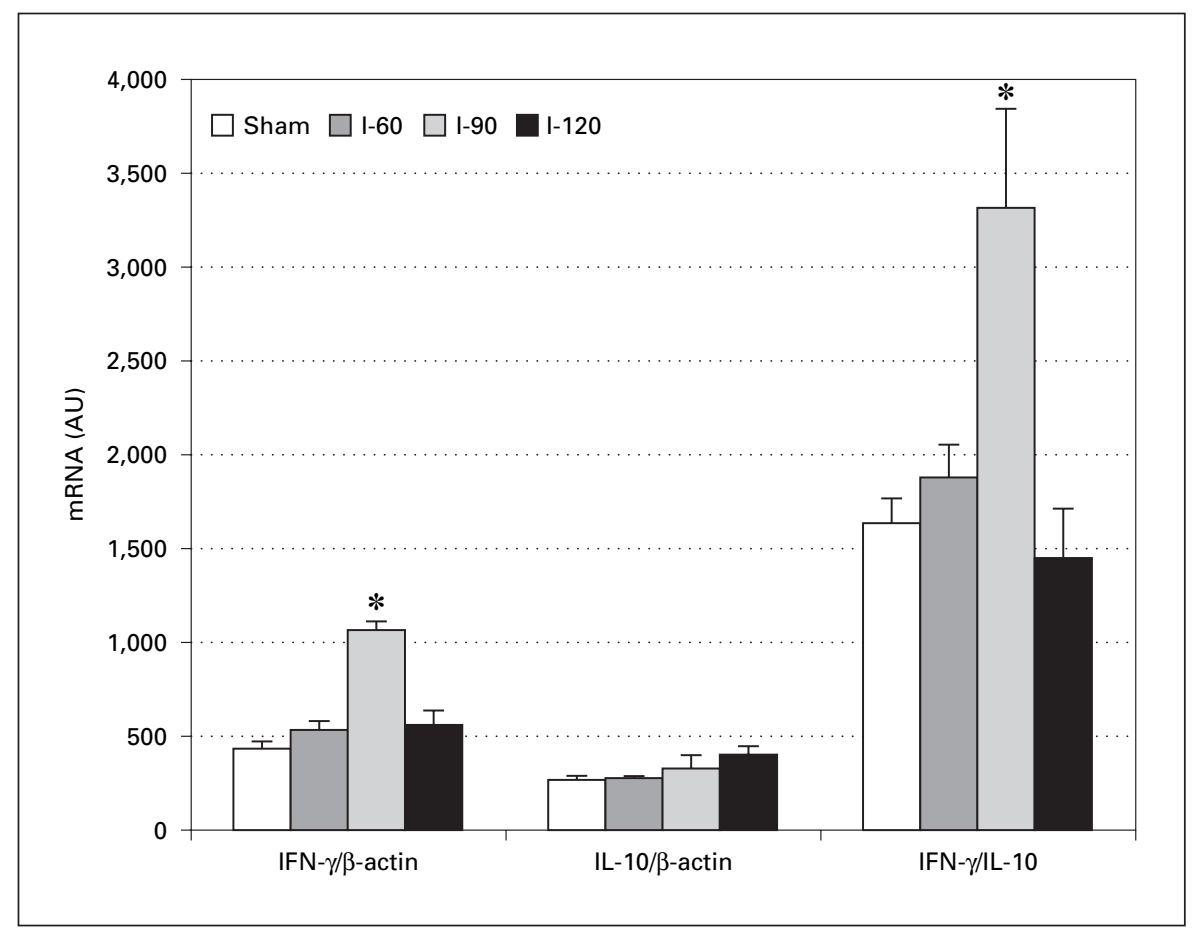

The HE staining of the injured lungs showed the typical formation of pulmonary edema in different stages. The alveoli were filled with a homogenous, generally acellular, eosinophilic fluid (fig. 7a, b). However, the morphological extent of reperfusion injury after 60, 90 and $120 \mathrm{~min}$ of ischemia differed greatly and did not correlate with the functional data. All sham-operated controls were identified and showed collapsed alveoli due to the large amount of elastic fibers in the rat lung (fig. 7c, d).

\section{Discussion}

Various studies describe the assessment of lung edema by transthoracic bioimpedance measurements in pulmonary critical care, but the method has been found to be critical in lung tissue $[17,18]$. Measurements depend on the variations of air volume within the tissue, on a number of factors including body weight and position, lung volume and pleural effusions. Compared to the transthoracic bioimpedance method, our microwave reflectometry system requires the contact between probe and tissue, and an application to patients is only possible during surgical operations with an open thorax. But microwave reflectometry gathers information directly from the tissue and the reflection coefficient depends on the dielectric properties of the lung. The main contribution to the dielectric properties of lung tissue beyond $1 \mathrm{GHz}$ is the polarization of water molecules because other contributions to the dielectric spectrum disappear due to their relaxation frequency in the $\mathrm{MHz}$ region [14]. The dielectric permittivity $\varepsilon_{w-t i s s u e}$ of lung tissue in the $\mathrm{GHz}$ region can be changed by changing the volume fraction of the nonpolar matter or the volume fraction of water as described by the mixture formula in equation 3. Changes in ion composition during ischemia are in the order of magnitude of millimoles per liter which has only small effects on the volume fraction. The conductivity of the electrolytes is mainly affected by this ion composition change but their effect on the real part of the complex dielectric permittivity is small (see equation 1). Therefore, data analysis with our model enables the online monitoring of lung edema by monitoring the dielectric properties of water molecules and quantification of the DMC is possible. However, there are some experimental sources of error which might reduce measurement accuracy and impede a better correlation between $D M C_{\text {diel }}$ and $D M C_{\text {weight }}$. For instance, dielectric lung properties showed a jitter due to the spirometric state of inspiration and expiration. Jitter frequency from artificial ventilation was $80 / \mathrm{min}$. One sweep of the network analyzer HP $8753 \mathrm{C}$ took $25 \mathrm{~s}$ so 

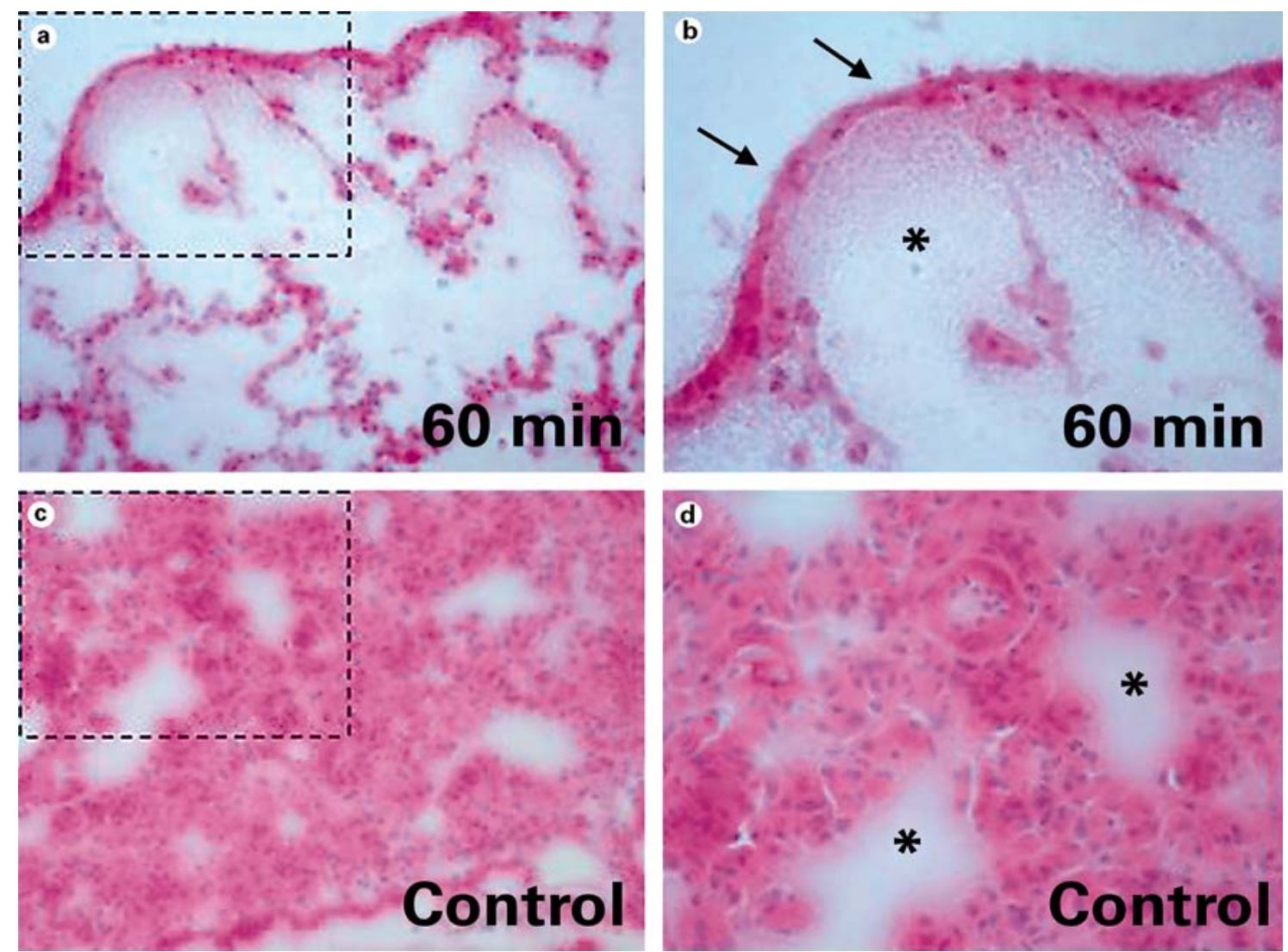

Fig. 7. HE staining of injured lungs and controls. a, b The subpleural section shows a pulmonary edema after $60 \mathrm{~min}$ of ischemia. The alveoli are distended and filled with a homogenous, generally acellular, eosinophilic fluid. The arrows mark the pleural epithelium. Original magnification $\times 200$ and $\times 400$ (insert). c, d Parenchymal section of sham-operated controls. All controls showed collapsed alveoli with a minimal fluid content (asterisks). Original magnification $\times 200$ and $\times 400$ (insert).

that the jitter affected each spectrum. We overcame this problem by using a curve fitting method [19] to calculate the averaged dielectric permittivity $\varepsilon_{w-t i s s u e}$. Another error source was the contact between the coaxial line probe and the surface of the ventilated lung. In our setup, the probe was fixed by an inelastic carrier and safe contact to the lung tissue surface required a moderate force. However, the pressure tolerance of lung tissue is very small and in some experiments the contact area was slightly deformed. On the other hand, the contact was not sufficient in the case of too small a pressure. The main error source of the method of drying and weighing was due to the varying amount of liquid on the surface of the small lung samples which distorted the dry-to-wet ratio. In spite of these deficiencies, the Bland-Altman plot in figure 3 shows that $95 \%$ of all measured differences between $D M C_{\text {weight }}$ and $D M C_{\text {diel }}$ were found in an interval of $\pm 2.3 \%$. Therefore, the method of measurement of $D M C_{\text {diel }}$ by microwave reflectometry is sensitive enough to detect differences in absolute DMC between the control group (sham: $19.1 \pm$ $1.50 \%$ ) and lung tissue strongly damaged by ischemia (I120: $12.8 \pm 0.60 \%$; fig. 5).

The parameter $D M C_{\text {diel }}$ seems to be sensitive enough to detect a significant increase in lung edema in I-90 compared to controls during reperfusion (fig. $5 ; \mathrm{p}<0.05$ ) and therefore it could be a helpful diagnostic tool to assess lung injury during postischemic reperfusion.

Warm ischemic tolerance of the nonventilated lung is described to be up to several hours [5-7]. Within this period we found that $90 \mathrm{~min}$ of lung ischemia at $37^{\circ} \mathrm{C}$ results in significant and reproducible reperfusion injury in all investigated parameters (fig. 3-6). Animals of the I-60 group did show lung injury at the start of reperfusion but recovered more and more during the reperfusion period 
of 2 h (fig. 2-4). Van Raemdonck et al. [5] compared the influence of an increasing postmortem interval on graft function in an isolated, room-air-ventilated rabbit lung model during blood reperfusion and found no significant differences after 1-hour ischemia compared to nonischemic lungs. There are several possible reasons for the different findings, e.g. in vivo versus the ex vivo animal model, and different organ temperatures $\left(37^{\circ} \mathrm{C}\right.$ vs. room temperature). All 3 animals of I-120 died within the first $30 \mathrm{~min}$ of reperfusion. A significant increase in lung weight gain with marked edema in the histological crosssections and a significant decrease in arterial oxygenation has been shown during this period. However, no changes have been observed in IFN- $\gamma$ and IL-10 mRNA expression levels in lung tissue. Both, the higher extent of ischemia-reperfusion injury and the short duration of the reperfusion period seemed to limit the alteration of mRNA expression. Palazzo et al. [20] demonstrated in a model of left lung ischemia-reperfusion in dogs that a period of $120 \mathrm{~min}$ of warm ischemia results in significant lung injury also of the contralateral lung, but this was not at all close to being lethal. These findings are similar to others, which limit the maximum safe warm ischemic period of deflated lungs to $2 \mathrm{~h}[6,21-23]$. However, all authors investigated lung ischemia at room temperature $\left(20-22^{\circ} \mathrm{C}\right)$ resulting in significantly lower organ temperatures. This differs significantly from our model, in which organ temperature is kept at $37 \pm 0.2^{\circ} \mathrm{C}$. This temperature was always reached within the first $25-35 \mathrm{~min}$ of ischemia (fig. 2). Circulating air at the opened thorax might influence ischemic tolerance of the lung. This problem has been overcome by Date et al. [24] using a different approach. A cooling jacket for lung grafts during the reimplantation period was used, and rewarming of the graft was prevented compared to no cooling or intermittent saline cooling [24].
Factors beside temperature which might additionally influence ischemic tolerance include operative preparation of hilar structures and well-being of the animal. Compared to the model of Eppinger et al. [2], no dissection of hilar structures of the right lung (vessels and bronchus) was carried out in our model. This makes our model easier to use, limits the dropout rate and limits major operative damage to these structures.

According to the theory of West and Dollery [25], positioning influences the distribution of ventilation and perfusion of both lungs significantly. Therefore, we presumed that the animal in a supine position has a more homogenous perfusion and ventilation on each lung side in comparison to side positioning, especially after injury of one side $[2,6,20]$.

\section{Conclusions}

Warm ischemic time tolerance of the lung at $37^{\circ} \mathrm{C}$ was found to be between 60 and $90 \mathrm{~min}$. Within the first $2 \mathrm{~h}$ of reperfusion, a significant increase in proinflammatory mediators on the molecular level has been observed, accompanied by loss of oxygenation and gain of lung edema. In this case, the measurement of pulmonary edema by microwave reflectometry could be a helpful diagnostic tool to assess lung injury during surgical operations with an open thorax.

\section{Acknowledgements}

Parts of this work have been funded by the junior investigators' grant of the Clinical Medical Faculty Mannheim and the Kurt Bast stipendium, University of Heidelberg. The authors would like to thank G. Rothkegel and B. Heidrich for providing logistic assistance.

\section{References}

1 DeMeo DL, Ginns LC: Lung transplantation at the turn of the century. Annu Rev Med 2001; 52:185-201

2 Eppinger M, Jones M, Deeb GM, Bollinger S, Ward P: Pattern of injury and role of neutrophils in reperfusion injury of rat lung. J Surg Res 1995;58:713-718.

3 Trulock EP: Lung transplantation. Am J Respir Crit Care Med 1997;1553:789-818.

4 Wichert PV: Studies on the metabolism of ischemic rabbit lungs: conclusions for lung transplantation. J Thorac Cardiovasc Surg 1972;63: 285-291.
5 Van Raemdonck DE, Janis NC, De Leyn PR, Flameng W, Lerut TE: Warm ischemic tolerance in collapsed pulmonary grafts is limited to 1 hour. Ann Surg 1998;228:788-796.

6 Yamazaki F, Wada H, Aoki M, Inui K, Hitomi S: An evaluation of the tolerance of the autotransplanted canine lung against warm ischemia. Jpn J Surg 1989;19:326-333.

7 D'Armini AM, Tom EJ, Roberts CS, Henke DC, Lemasters JJ, Egan TM: When does the lung die? Time course of high energy phosphate depletion and relationship to lung viability after ‘death'. J Surg Res 1995;59:468-474.
8 Eppinger MJ, Deeb GM, Bolling SF, Ward PA: Mediators of ischemia-reperfusion injury of rat lung. Am J Pathol 1997;150:1773-1784.

9 Schaefer M, Nowak K, Kherad B, Gross W, Post S, Gebhard MM: Monitoring water content of rat lung tissue in vivo using microwave reflectometry. Med Biol Eng Comput 2004;42: 577-580.

10 Matsuda S, Tani Y, Yamada M, Yoshimura K, Arizono N: Type 2-biased expression of cytokine genes in lung granulomatous lesions induced by Nippostrongylus brasiliensis infection. Parasite Immunol 2001;23:219-226. 
11 Schaefer M, Gross W, Ackemann J, Gebhard MM: The complex dielectric spectrum of heart tissue during ischemia. Bioelectrochemistry 2002; 58:171-180.

12 Böttcher CJF, Bordewijk P: Theory of Electric Polarisation, ed 1. Amsterdam, Elsevier; 1978.

13 Kaatze U, Uhlendorf V: Dielectric properties of water at microwave frequencies. Z Phys Chem 1981;126:152-165.

14 Rigaud B, Morucci JP, Chauveau N: Bioelectrical impedance techniques in medicine. Crit Rev Biomed Eng 1996;24:257-351.

15 Schaefer M, Gross W, Preuss M, Ackemann J, Gebhard MM: Monitoring of water content and water distribution in ischemic hearts. Bioelectrochemistry 2003;61:85-92.

16 Bland JM, Altman DG: Statistical methods for assessing agreement between two methods of clinical measurement. Lancet 1986;i:307310 .
17 Nierman DM, Eisen DI, Fein ED, Hannon E, Mechanick JI, Benjamin E: Transthoracic bioimpedance can measure extravascular lung water in acute lung injury. J Surg Res 1996;65: 101-108.

18 Fein A, Grossman RF, Jones JG, Goodman PC, Murray JF: Evaluation of transthoracic electrical impedance in the diagnosis of pulmonary edema. Circulation 1979;60:1156-1160.

19 Miura N, Shioya S, Kurita D, Shigematsu T, Mashimo S: Time domain reflectometry: measurement of free water in normal lung and pulmonary edema. Am J Physiol 1999;276:L207_ L212.

20 Palazzo R, Hamvas A, Shuman T, Kaiser L, Cooper J, Schuster DP: Injury in nonischemic lung after unilateral pulmonary ischemia with reperfusion. J Appl Physiol 1992;72:612620.
21 Blades B, Beattie EJ Jr, Hill RP, Thistlethwaite R: Ischemia of the lung. Ann Surg 1952;136: 56-62.

22 Fonkalsrud EW, Higashijima I, Sarwat AK, Arima E, Sanchez M: Evaluation of pulmonary function in the ischemic, nonventilated canine lung. Surgery 1974; 76:527-532.

23 Kondo Y, Turner MD, Cockrell JV, Hardy JD: Ischemic tolerance of the canine autotransplanted lung. Surgery 1974;76:447-453.

24 Date H, Matsumura A, Manchester JK, Obo H, Lima O, Cooper JM, Sundaresan S, Lowry $\mathrm{OH}$, Cooper JD: Evaluation of lung metabolism during successful twenty-four-hour canine lung preservation. J Thorac Cardiovasc Surg 1993;105:480-491.

25 West JB, Dollery CT: Distribution of blood flow and ventilation-perfusion ratio in the lung, measured with radioactive carbon dioxide. J Appl Physiol 1960;15:405-410. 